\title{
Hypothalamic amenorrhea with normal body weight: ACTH, allopregnanolone and cortisol responses to corticotropin- releasing hormone test
}

Blazej Meczekalski, Arianna Tonetti, Patrizia Monteleone, Francesca Bernardi, Stefano Luisi, Massimo Stomati, Michele Luisi ${ }^{1}$, Felice Petraglia ${ }^{2}$ and Andrea R Genazzani

Department of Reproductive Medicine and Child Development, Section of Gynecology and Obstetrics, University of Pisa, Pisa, Italy,

${ }^{1}$ CNR, Endocrine Research Unit, Pisa, Italy and ${ }^{2}$ Department of Surgical Sciences, Chair of Obstetrics and Gynecology, University of Udine, Italy

(Correspondence should be addressed to A R Genazzani, Department of Reproductive Medicine and Child Development, Section of Gynecology and Obstetrics, University of Pisa, Via Roma 35, 56100, Pisa, Italy; Email: a.genazzani@obgyn.med.unipi.it)

(B Meczekalski is now at Department of Gynecological Endocrinology, University School of Medical Sciences in Poznan, Poland)

\begin{abstract}
Objective: Hypothalamic amenorrhea (HA) is a functional disorder caused by disturbances in gonadotropin-releasing hormone $(\mathrm{GnRH})$ pulsatility. The mechanism by which stress alters $\mathrm{GnRH}$ release is not well known. Recently, the role of corticotropin-releasing hormone (CRH) and neurosteroids in the pathophysiology of HA has been considered. The aim of the present study was to explore further the role of the hypothalamic-pituitary-adrenal axis in HA.

Design: We included 8 patients (aged $23.16 \pm 1.72$ years) suffering from hypothalamic stress-related amenorrhea with normal body weight and 8 age-matched healthy controls in the follicular phase of the menstrual cycle.

Methods: We measured basal serum levels of FSH, LH, and estradiol and evaluated ACTH, allopregnanolone and cortisol responses to CRH test in both HA patients and healthy women.

Results: Serum basal levels of FSH, LH, and estradiol as well as basal levels of allopregnanolone were significantly lower in HA patients than in controls $(P<0.001)$ while basal ACTH and cortisol levels were significantly higher in amenorrheic patients with respect to controls $(P<0.001)$. The response (area under the curve) of ACTH, allopregnanolone and cortisol to CRH was significantly lower in amenorrheic women compared with controls $(P<0.001, P<0.05, P<0.05$ respectively).

Conclusions: In conclusion, women with HA, despite the high ACTH and cortisol levels and, therefore, hypothalamus-pituitary-adrenal axis hyperactivity, are characterized by low allopregnanolone basal levels, deriving from an impairment of both adrenal and ovarian synthesis. The blunted ACTH, allopregnanolone and cortisol responses to CRH indicate that, in hypothalamic amenorrhea, there is a reduced sensitivity and expression of $\mathrm{CRH}$ receptor. These results open new perspectives on the role of neurosteroids in the pathogenesis of hypothalamic amenorrhea.
\end{abstract}

European Journal of Endocrinology 142 280-285

\section{Introduction}

The role of neurosteroids in reproductive disorders is still under discussion. The term neurosteroids has been applied to steroids synthesized in the brain either de novo or by the in situ metabolism of blood-borne precursors (1). Neurosteroids can act through either a genomic or a non-genomic effect. The genomic effect is mediated by a cytoplasmatic receptor and the non-genomic effect by the direct interaction with the GABA-A receptor. Allopregnanolone ( $3 \alpha$-hydroxy- $5 \alpha$-pregnan-20-one) is the most diffuse neurosteroid, acting as an agonist on the GABA-A receptor. Experimental studies have shown that allopregnanolone is involved in stress, mood and sexual behavior $(2-4)$.
The changes in brain allopregnanolone concentration in female rats during the estrous cycle (5) and the effect provoked by the intracerebroventricular injection of allopregnanolone or its antiserum on rat ovulatory function (6), suggest that brain allopregnanolone is involved in modulating reproductive function. Serum allopregnanolone levels increase in response to corticotropin-releasing hormone $(\mathrm{CRH})$ or adrenocorticotropin $(\mathrm{ACTH})$ tests in fertile subjects, thus indicating that the adrenals are a major source of circulating allopregnanolone. On the other hand, the ovary contributes to allopregnanolone synthesis in rats and humans. In fact, plasma concentrations of this steroid hormone vary during the menstrual cycle, with higher levels in the luteal phase than in the follicular 
phase $(0.79 \pm 0.30 \mathrm{nmol} / \mathrm{l}$ in the follicular phase and $3.69 \pm 0.96 \mathrm{nmol} / \mathrm{l}$ in the luteal phase) (7). Moreover, higher levels have also been observed during pregnancy (8). Finally, it is possible to assess allopregnanolone directly in rat ovarian tissue (9). It has been demonstrated that allopregnanolone levels in postmenopausal women are similar to those observed in fertile subjects in the follicular phase. There are no data in the literature concerning circulating allopregnanolone levels in hypothalamic amenorrhea. Hypothalamic amenorrhea (HA) is a functional disorder characterized by an altered gonadotropin-releasing hormone $(\mathrm{GnRH})$ pulsatility (10), improper pulsatile gonadotropin secretion (follicle-stimulating hormone (FSH) and luteinizing hormone (LH)) and, in turn, altered ovarian steroidogenesis (11). A GnRH pulsatility within a critical range (frequency and amplitude) normally stimulates gonadotropin secretion, thus ensuring a normal menstrual cycle (12). It is known that psychological and physical stress may lead to amenorrhea by influencing $\mathrm{GnRH}$ pulsatility (13). Several neuroendocrine changes occur in HA, such as modifications of opioid peptide, melatonin (14-16) or of CRH levels $(17,18)$. CRH, a 41 amino acid peptide, is secreted by the hypothalamus (supraoptic, paraventricular and arcuatus nuclei) and is responsible for the pituitary secretion of preopiomelanocortin-related peptides (19). CRH inhibits GnRH secretion directly or indirectly by increasing $\beta$-endorphin secretion, thus suppressing the electrophysiological activity of the GnRH pulse generator (20-22).

The aim of the present study was to investigate ACTH, allopregnanolone and cortisol responses to CRH test in women with HA compared with fertile age-matched women.

\section{Subjects and materials}

\section{Subjects}

In this study, we included women $(n=8)$ with hypothalamic amenorrhea of at least 6 months duration (aged 21-26 years: mean 23.2 \pm 1.72 years) and age-matched normal women in the follicular phase of the menstrual cycle $(n=8)$. All patients and healthy volunteers gave written informed consent to the investigation, which was approved by the local Ethical Committee. All subjects had a careful medical history performed. Menstrual status (age of menarche, regularity of cycles, duration of amenorrhea), nutritional status (height, weight, body mass index (BMI)), exercise and stressful life events were evaluated in all subjects. Amenorrheic women had a history of stressful events which preceded the onset of amenorrhea, such as familiar, scholastic or working problems. The patients underwent psychological testing including the Structural Clinical Interview for the DSM IV, to rule out significant psychiatric diseases that might affect the hypothalamic-pituitary-adrenal axis. The diagnosis of hypothalamic amenorrhea was confirmed by studying the typical hormonal profile (low levels of FSH, LH and estradiol) and characteristic medical history. The duration of amenorrhea ranged from 12 to 36 months (mean 19.0 \pm 9.61 months). The mean \pm s.E.M. weight of the patients was within the normal range $\left(61.7 \pm 6.43 \mathrm{~kg}\right.$; BMI: $\left.22.5 \pm 1.37 \mathrm{~kg} / \mathrm{m}^{2}\right)$ (Table 1$)$. None had a history of weight loss prior to the study nor did they engage in regular exercise, have any chronic medical disease, anorexia nervosa, clinical depression, endocrine or thyroid disease. None of the patients had taken any hormonal medication 6 months prior to the study.

The 8 age-matched controls were healthy normally cyclic females (menstrual cycle duration from 28 to 32 days). The body weight of control patients was in the normal range (mean $60.7 \pm 7.0 \mathrm{~kg}$; BMI: $22.5 \pm 1.9 \mathrm{~kg} / \mathrm{m}^{2}$ ) (Table 1$)$. None of the controls had taken any hormonal preparation since at least 6 months prior to the study. Blood samples were taken in the early follicular phase of the menstrual cycle (days 4-6 of menstrual cycle).

\section{Protocol}

Basal blood samples for FSH, LH, estradiol, ACTH, cortisol and allopregnanolone measurement were drawn between 08.00-09.00 h, after overnight fasting. $\mathrm{CRH}$ test was performed by inserting a catheter into an anticubital vein while slow infusion of $0.9 \%$ saline solution was started. Two baseline blood samples were obtained at $-15 \mathrm{~min}$ and time zero. Further blood samples were collected 15, 30, 60, 90 and $120 \mathrm{~min}$ after an intravenous bolus injection of human CRH $(100 \mu \mathrm{g})$ (Clinalfa AG, Laufelfingen, Switzerland). Blood samples were transferred into glass tubes, centrifuged $(15 \mathrm{~min}$ at $3000 \mathrm{~g})$ and stored at $-70^{\circ} \mathrm{C}$ until assessment of ACTH, allopregnanolone and cortisol levels.

\section{FSH, LH, estradiol, ACTH and cortisol assays}

All hormones were assayed using RIA methods (Radim Spa, Pomezia, Italy). FSH intra- and interassay coefficients of variation were $4.2 \%$ and $6.2 \%$ respectively; sensitivity was $0.18 \mathrm{mIU} / \mathrm{ml}$. LH intra- and interassay coefficients of variation were $7.8 \%$ and $8.2 \%$ respectively; sensitivity was $0.2 \mathrm{mIU} / \mathrm{ml}$. Estradiol intra- and interassay coefficients of variation were $2.0 \%$ and $2.8 \%$ respectively; sensitivity was $10 \mathrm{pg} / \mathrm{ml}$. ACTH intra- and interassay coefficients of variation were below $6.7 \%$; sensitivity was $10 \mathrm{pg} / \mathrm{ml}$. For cortisol, the sensitivity was $0.9 \mathrm{nmol} / \mathrm{l}$ and the intra- and interassay coefficients of variation were $3.6 \%$ and $7.3 \%$ respectively.

\section{Allopregnanolone assay}

Analytical grade solvents were purchased from Merck (Darmstadt, Germany); C-18 Sep-Pak cartridges were 
Table 1 Clinical characteristics and FSH, LH, estradiol and other baseline hormonal values of women with hypothalamic amenorrhea and control subjects. Values are expressed as means \pm S.D.

\begin{tabular}{lcc}
\hline Variable & $\begin{array}{c}\text { Patients with hypothalamic amenorrhea } \\
(n=8)\end{array}$ & $\begin{array}{c}\text { Control } \\
(n=8)\end{array}$ \\
\hline Age (years) & $23.2 \pm 1.72$ & $23.8 \pm 6.27$ \\
Height $(\mathrm{cm})$ & $168.2 \pm 5.41$ & $167.2 \pm 5.30$ \\
Weight $(\mathrm{kg})$ & $61.7 \pm 6.43$ & $60.7 \pm 7.0$ \\
BMI $\left(\mathrm{kg} / \mathrm{m}^{2}\right)$ & $22.5 \pm 1.37$ & $22.5 \pm 1.9$ \\
Duration of amenorrhea (months) & $19.0 \pm 9.61$ & - \\
FSH (IU/l) & $2.6 \pm 1.2^{* *}$ & $8.61 \pm 1.8$ \\
LH (IU/l) & $2.91 \pm 0.77^{\star *}$ & $14.05 \pm 3.28$ \\
Estradiol $(\mathrm{pg} / \mathrm{ml})$ & $15.5 \pm 4.13^{\star *}$ & $47.66 \pm 8.66$ \\
ACTH $(\mathrm{nmol} / \mathrm{l})$ & $4.74 \pm 0.95^{\star *}$ & $2.19 \pm 0.76$ \\
Allopregnanolone $(\mathrm{nmol} / \mathrm{l})$ & $0.32 \pm 0.11^{* *}$ & $0.75 \pm 0.16$ \\
Progesterone $(\mathrm{pg} / \mathrm{ml})$ & $0.49 \pm 0.24$ & $0.65 \pm 0.18$ \\
Cortisol $(\mathrm{nmol} / \mathrm{l})$ & $47.91 \pm 10.32^{* *}$ & $30.27 \pm 7.98$ \\
\hline
\end{tabular}

${ }^{\star *} P<0.001$ vs control.

obtained from Waters Corporation (Milford, MA, USA). Standard allopregnanolone was purchased from Sigma Chemical Co. (St Louis, MO, USA) and pregnan- $3 \alpha-$ ol-20-one, $\quad 5 \alpha-\left[9,11,12,-{ }^{3} \mathrm{H}(\mathrm{N})\right] \quad(45 \mathrm{Ci} / \mathrm{nmol})$ from Amersham (Amersham, Bucks, UK). The polyclonal antisera, raised in sheep against allopregnanolone carboxymethyl ether coupled to BSA, were kindly provided by Dr RH Purdy. Serum samples $(1 \mathrm{ml})$ were thawed. The assay was performed as previously described (23).

The sensitivity of the assay, expressed as a minimal amount of allopregnanolone distinguishable from the zero sample with $95 \%$ probability, was $15-20 \mathrm{pg} /$ tube. The mean percentage recovery of tritiated allopregnanolone after extraction and chromatography was $85.5 \pm 12.7$ and the intra- and interassay coefficients of variation of the allopregnanolone assay were $7.2 \%$ and $9.1 \%$ respectively.

\section{Statistics}

Basal hormonal evaluations were expressed as means \pm S.D.; allopregnanolone, ACTH, and cortisol responses to CRH test were calculated as $\triangle$ AUC (area under the curve (AUC) after CRH stimulation-basal AUC) and compared between controls and HA by means of Student's $t$-test. Significant variations of mean ACTH, allopregnanolone and cortisol during $\mathrm{CRH}$ test were analyzed with ANOVA. The Bonferroni test was used to compare ACTH, allopregnanolone and cortisol means at all times with the mean at baseline. Alpha was set at 0.05. Multivariate ANOVA (MANOVA) was used to verify whether the means of ACTH, allopregnanolone and cortisol during the test were different in HA compared with control subjects.

\section{Results}

Serum FSH, LH, $\beta$-estradiol, ACTH, allopregnanolone and cortisol levels are shown in Table 1. Basal serum allopregnanolone levels were significantly lower in HA than in controls $(P<0.001)$ (Table 1$)$. On the other hand, basal ACTH and cortisol levels were significantly higher in HA than in controls $(P<0.001)$ (Table 1$)$. No significant differences were observed between progesterone levels in HA and in controls (Table 1) and no correlation existed between progesterone and allopregnanolone levels either in controls or in HA. The responses of ACTH, allopregnanolone, and cortisol to CRH stimulation test are shown in Fig. 1.

In control subjects, ACTH, allopregnanolone and cortisol levels increased significantly $(P<0.001)$; in particular, means at times 30,60, and $90 \mathrm{~min}$ were significantly higher than means at baseline for allopregnanolone and cortisol, while ACTH was increased at 15,30 , and $60 \mathrm{~min}$. In HA, no significant differences in ACTH and allopregnanolone were observed during the test, while cortisol increased at $30 \mathrm{~min}$. With the MANOVA, the means of ACTH, allopregnanolone and cortisol were significantly different between $\mathrm{HA}$ and control subjects at different times during CRH test.

ACTH, allopregnanolone and cortisol responses $(\triangle \mathrm{AUC})$ to $\mathrm{CRH}$ test in amenorrheic women were significantly lower than in controls (Fig. 2).

\section{Discussion}

The present study shows that women with HA have lower allopregnanolone basal levels, although ACTH and cortisol levels are higher than in healthy women. Moreover, amenorrheic women are characterized by blunted ACTH, allopregnanolone, and cortisol responses to $\mathrm{CRH}$. The present study confirms previous reports of hypercortisolemia in women with HA (24-26). Other studies showed no differences in ACTH basal levels between HA patients and normal women $(27,28)$. The assessment of urinary free cortisol and nycthemeral measurement of ACTH and 

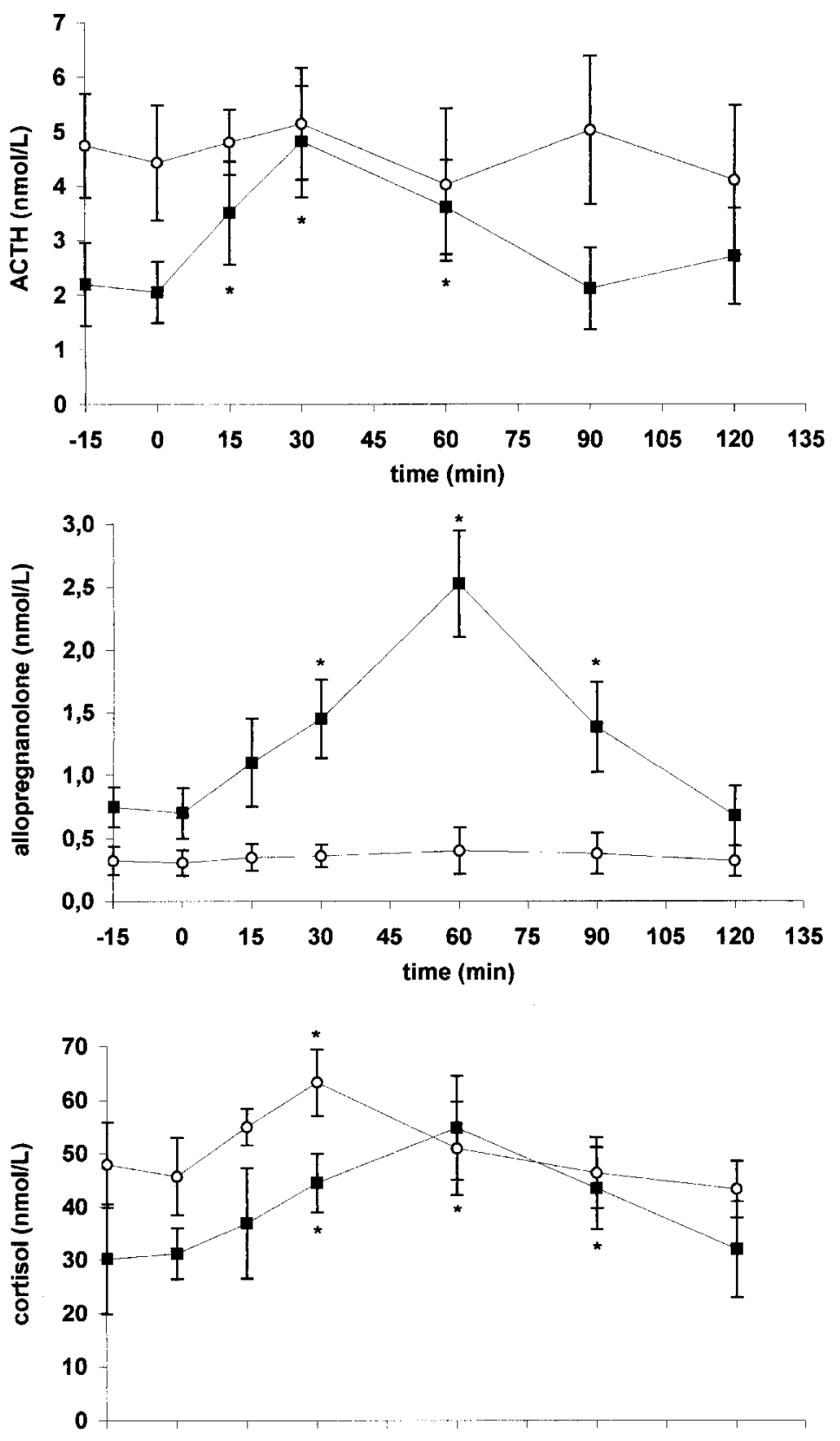

Figure 1 Mean \pm S.D. serum ACTH, allopregnanolone and cortisol responses to $\mathrm{CRH}$ in patients with hypothalamic amenorrhea $(O)$ and control women (ם). ${ }^{*} P<0.001$. cortisol could be helpful for a better understanding of the changes in ACTH and cortisol in HA.

The present study shows that basal allopregnanolone levels are reduced in HA. Allopregnanolone is a derivative of progesterone, synthesized in the gonads, adrenal cortex, and central nervous system (29, 30). The decrease in allopregnanolone could be related to a decreased progesterone availability in HA. The present study rules out this possibility because progesterone levels were not significantly different between $\mathrm{HA}$ and control women in the follicular phase, and no correlation was observed between allopregnanolone and progesterone levels either in controls or in HA.
The effects provoked by an intracerebroventricular injection of allopregnanolone or its antiserum on rat ovulatory function strongly indicate that there is a correlation between central nervous system levels of allopregnanolone and reproductive function $(6,23)$. Certainly changes in brain allopregnanolone concentration are caused mostly by changes in the supply of precursors within the brain, as demonstrated by Corpechot et al. (31), but one cannot ignore the fact that central levels of this neurosteroid may be influenced by reproductive function itself, as suggested by the changes in brain allopregnanolone concentration that occur in female rats during sexual maturation 

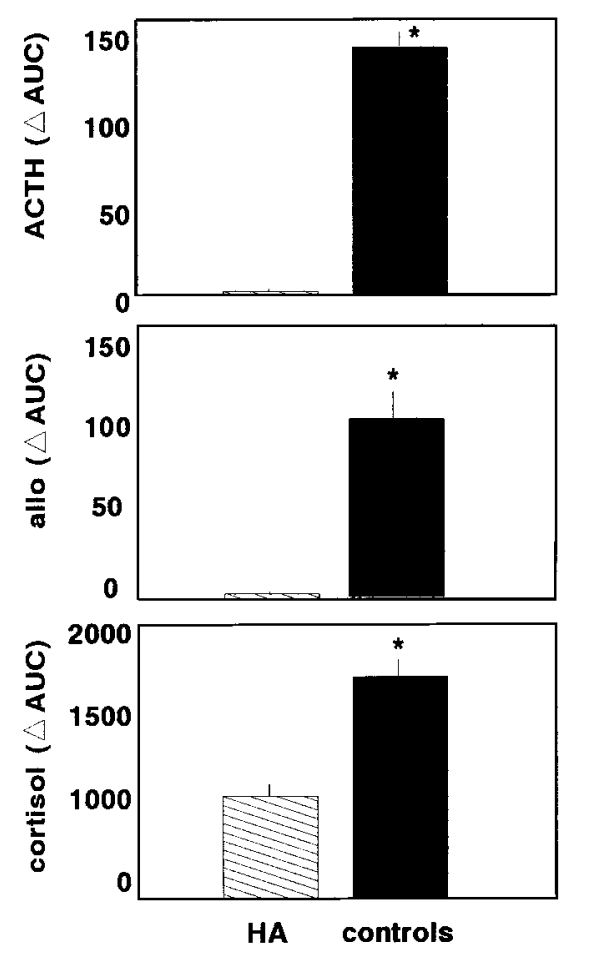

Figure 2 The mean \pm S.D. responses (in $\mathrm{nmol} / \mathrm{l} \times \mathrm{min}$ ) of $\mathrm{ACTH}$, allopregnanolone (allo), and cortisol to $\mathrm{CRH}$ test have been shown as $\triangle A U C$. Hatched bars, amenorrheic patients (HA), solid bars, control group. ${ }^{*} P<0.001$ compared with HA group.

and the estrous cycle (5). Moreover, in humans, it has been reported that circulating allopregnanolone levels vary throughout the menstrual cycle. The luteal phase is characterized by high levels of allopregnanolone. There are controversial results regarding the possible role of allopregnanolone in the pathogenesis of premenstrual-related anxiety (32-35). A recent study revealed that patients, both male and female, with major unipolar depression have about $60 \%$ less allopregnanolone in their cerebrospinal fluid than control subjects. Allopregnanolone cerebrospinal fluid levels increased after treatment with selective serotonin reuptake inhibitors but progesterone levels did not, indicating a specific role of neuroactive steroid biosynthesis in the pathogenesis of anxiety in this mood disorder (36). It has been hypothesized that the mood changes observed in women during the third trimester of pregnancy may be correlated with an increase in serum allopregnanolone levels and with an increase in GABA-A receptor sensitivity to GABA-agonists (8).

Allopregnanolone may affect numerous brain areas and modulate sexual behavior, memory, mood changes and response to stress (37). Acute stress causes an increase in allopregnanolone levels in rat brain and plasma. Allopregnanolone exerts barbiturate-like effects with anxiolytic, hypnotic and anesthetic effects by enhancing GABAergic transmission, acting as an endogenous stress protective agent (38). The low allopregnanolone levels observed in HA women may be a consequence of the exposure to chronic stress in these patients; the reduced circulating allopregnanolone levels, in turn, determine a reduction in its antistress protective effects.

The present study confirms that women with HA have an attenuated ACTH and cortisol response to CRH $(27,28)$. A similar blunted response to CRH also occurs in patients with anorexia nervosa or depression, both characterized by endogenous $\mathrm{CRH}$ hyperactivity (39-41). Different hypotheses have been proposed to try to explain what causes high ACTH and cortisol resting levels and blunted ACTH and cortisol responses to $\mathrm{CRH}$ in HA. The chronic exposure to high levels of $\mathrm{CRH}$ probably determines a decrease in sensitivity and a reduced expression of $\mathrm{CRH}$ receptor. In addition, the low levels of ACTH in response to $\mathrm{CRH}$ fail to stimulate both cortisol and allopregnanolone release. Finally, one cannot exclude an altered glucocorticoid receptor function in HA.

In conclusion, women with HA are characterized by lower basal allopregnanolone and higher ACTH and cortisol levels with respect to controls, and by impaired allopregnanolone, ACTH and cortisol response to CRH. Further studies are necessary to better define the role of allopregnanolone in the setting of HA.

\section{References}

1 Baulieu EE. Steroid hormones in the brain: several mechanisms? In Steroid Hormone Regulation of the Brain, pp 3-10. Eds K Fuxe, JA Gustafsson \& A Wetterberg. Oxford: Pergamon Press, 1981.

2 Mellon SH. Neurosteroids: biochemistry, modes of action, and clinical relevance. Journal of Clinical Endocrinology and Metabolism 199478 1003-1008.

3 Barbaccia ML, Roscetti G, Trabucchi M, Mostallino MC, Concas A, Purdy $\mathrm{RH}$ et al. Time-dependent changes in rat brain neuroactive steroid concentrations and GABA-A receptor function after acute stress. Neuroendocrinology 199663 166-172.

4 Barbaccia ML, Roscetti G, Trabucchi M, Purdy RH, Mostallino MC, Concas A et al. The effects of inhibitors of GABAergic transmission and stress on brain and serum allopregnanolone concentrations. British Journal of Pharmacology 1997 $1201582-1588$.

5 Palumbo MA, Salvestroni C, Gallo R, Ai-Li Guo, Genazzani AD, Artini PG et al. Allopregnanolone concentration in hippocampus of prepubertal rats and female rats throughout the estrous cycle. Journal of Endocrinological Investigation 199518 853-856.

6 Genazzani AR, Palumbo MA, de Micheroux AA, Artini PG, Criscuolo M, Ficarra G et al. Evidence for a role for the neurosteroid allopregnanolone in the modulation of reproductive function in female rats. European Journal of Endocrinology 1995 133 375-380.

7 Genazzani AR, Petraglia F, Bernardi F, Casarosa E, Tonetti A, Nappi R et al. Circulating levels of allopregnanolone in humans: gender, age and endocrine influences. Journal of Clinical Endocrinology and Metabolism 199883 2099-2103.

8 Majewska MD. Neurosteroids: endogenous bimodal modulators of the GABA-A receptor. Mechanism of action and physiological significance. Progress in Neurobiology 199238 379-395.

9 Corpechot C, Young J, Calvel M, Wehrey C, Veltz JN, Touyer G et al. Neurosteroids: $3 \alpha$-hydroxy-5 $\alpha$-pregnan-20-one and its precursor in the brain, plasma, and steroidogenic glands of male and female rats. Endocrinology 1993133 1003-1009. 
10 Liu JH. Hypothalamic amenorrhea: clinical perspectives, pathophysiology and management. American Journal of Obstetrics and Gynecology $19901631732-1736$.

11 Reame N, Sauder SE, Kelch RP \& Marshall JC. Pulsatile gonadotropin secretion during the human menstrual cycle: evidence for altered frequency of gonadotropin-releasing hormone secretion. Journal of Clinical Endocrinology and Metabolism $198459328-337$.

12 Xia L, Van Vught D, Alston EJ, Luckhaus J \& Ferin M. A surge of $\mathrm{GnRH}$ accompanies the estradiol-induced gonadotropin surge in the Rhesus monkey. Endocrinology $19921312812-2820$.

13 Chrousos GP \& Gold PW. The concepts of stress and stress system disorders. Journal of the American Medical Association 1992267 1244-1252.

14 Laatikainen T, Virtanen T \& Apter D. Plasma immunoreactive beta-endorphin in exercise-associated amenorrhea. American Journal of Obstetrics and Gynecology 1986 154 94-97.

15 Russell JB, Mitchell DE \& Collins DC. The role of beta-endorphin and catechol estrogens on hypothalamic-pituitary axis in female athletes. Fertility and Sterility 198442 690-695.

16 Mortola JF, Laughlin GA \& Yen SSC. Melatonin rhythms in women with anorexia nervosa and bulimia nervosa. Journal of Clinical Endocrinology and Metabolism 199377 1540-1544.

17 Vale W, Spies J, Rivier C \& Rivier J. Characterization of a 41 residue ovine hypothalamic peptide that stimulates secretion of corticotropin and beta-endorphin. Science 1981213 1394-1397.

18 Saffran M \& Schally AV. The release of corticotropin by anterior pituitary in culture. Canadian Journal of Biochemistry and Physiology 195533 408-412.

19 Rivier C, Brownstein M, Spiess J, Rivier J \& Vale W. In vivo CRF induced secretion of adenocorticotropin, beta-endorphin and cortisol. Endocrinology $1982110272-278$.

20 Favrod-Coune CA, Gaillard RC, Langerin H, Jaquier MC \& Dolci W. Anatomical localization of corticotropin-releasing activity in the human brain. Life Sciences 198639 2475-2481.

21 Gambacciani M, Yen SSC \& Rasmussen DD. GnRH release from the mediobasal hypothalamus: in vitro inhibition by corticotropin releasing factor. Neuroendocrinology 198643 533-536.

22 Petraglia F, Sutton S, Vale W \& Plotsky P. Corticotropin releasing factor decreases plasma luteinizing hormone levels in female rats by inhibiting $\mathrm{GnRH}$ release into hypophyseal-portal circulation. Endocrinology $19871201083-1088$

23 Genazzani AR, Salvestroni C, Guo A-L, Palumbo M, Cela V, Casarosa E et al. Neurosteroids and regulation of neuroendocrine function. In The Brain: Source and Target for Sex Steroid Hormones, pp 83-91. Eds AR Genazzani, F Petraglia \& RH Purdy. Carnforth, UK: Parthenon Publishing, 1996.

24 Suh BY, Liu JH, Berga SL, Quigley ME, Laughlin GA \& Yen SSC. Hypercortisolism in patients with functional hypothalamic amenorrhea. Journal of Clinical Endocrinology and Metabolism $198866733-739$

25 Boesgard S, Mager C, Andersen AN, Djursig H \& Fengerr M. Cortisol secretion in patient with normoprolactinemic amenorrhea. Acta Endocrinologica 1988118 544-550.

26 Nappi RE, Petraglia F, Genazzani AD, D’Ambrogio G, Zara C \& Genazzani AR. Hypothalamic amenorrhea: evidence for a centra derangement of hypothalamic-pituitary-adrenal axis activity. Fertility and Sterility 199359 571-576.
27 Loucks AB, Mortola JF, Girton L \& Yen SSC. Alterations in the hypothalamic-pituitary-ovarian and hypothalamic-pituitaryadrenal axes in athletic women. Journal of Clinical Endocrinology and Metabolism 198968 402-411.

28 Biller BMK, Federoff HJ, Koening JI \& Klibanski A. Abnormal cortisol secretion and response to corticotropin releasing hormone in women with hypothalamic amenorrhea. Journal of Clinical Endocrinology and Metabolism 199070 311-317.

29 Robel P \& Baulieu EE. Neurosteroids: biosynthesis and function. Trends in Endocrinology and Metabolism 19945 1-8.

30 Baulieu EE \& Robel P. Neurosteroids: a new brain function? Journal of Steroid Biochemistry and Molecular Biology 199037 395-403.

31 Corpechot C, Collins BE, Carey MP, Tsouros A, Robel P \& Fry JP. Brain neurosteroids during the mouse estrous cycle. Brain Research $1997766276-280$.

32 Wang M, Seippel L, Purdy RH \& Backstrom T. Relationship between symptom severity and steroid variation in women with premenstrual syndrome: study on serum pregnenolone sulfate, $5 \alpha$-pregnan-3,20-dione and 3 $\alpha$-hydroxy-5 $\alpha$-pregnan-20-one. Journal of Clinical Endocrinology and Metabolism 199681 1076-1082.

33 Schmidt PJ, Purdy RH, Moore PH, Paul SM \& Rubinow DR. Circulating levels of anxiolytic steroids in the luteal phase in women with premenstrual syndrome and in control subjects. Journal of Clinical Endocrinology and Metabolism 199479 1256-1260.

34 Bicikova M, Dibbelt L, Hill M, Hampl R \& Starka L. Allopregnanolone in women with premenstrual syndrome. Hormone and Metabolic Research $199830227-230$.

35 Rapkin AJ, Morgan M, Goldman L, Brann DW, Simone D \& Mahesh VB. Progesterone metabolite allopregnanolone in women with premenstrual syndrome. Obstetrics and Gynecology 199790 709-714.

36 Uzunova V, Sheline Y, Davis JM, Rasmusson A, Uzunov DP, Costa E et al. Increase in the cerebrospinal fluid content of neurosteroids in patients with unipolar depression who are receiving fluoxetine or fluvaxamine. Proceedings of the National Academy of Sciences of the USA $1998953239-3244$.

37 Paul SM \& Purdy RH. Neuroactive steroids. FASEB Journal 19926 2311-2322.

38 Majewska MD, Harrison NL, Schwartz RD, Barker JL \& Paul SMN. Steroid hormones metabolites are barbiturane-like modulators of the GABA receptors. Science 1986232 1004-1007.

39 Mezey E \& Palkovits M. CRF-containing neurons in the hypothalamic paraventricular nucleus: regulation especially by catecholamines. Frontiers in Neuroendocrinology 1991 12 23-27.

40 Gold PW, Gwirtsman H, Avgerinos PC, Nieman LK, Galluci WT, Kaye $\mathrm{W}$ et al. Abnormal hypothalamic-pituitay-adrenal axis in anorexia nervosa. New England Journal of Medicine 1986314 1335-1342.

41 Rupprecht R, Lesh KP, Mukker U, Beck G, Beckman H \& Schulte HM. Blunted adrenocorticotropin but normal betaendorphin release after human corticotropin releasing hormone administration in depression. Journal of Clinical Endocrinology and Metabolism 198969 600-603.

Received 10 May 1999

Accepted 18 November 1999 